OPEN ACCESS

Edited by:

Yu Xiang George Kong,

The Royal Victorian Eye \& Ear

Hospital, Australia

Reviewed by:

Sirisha Senthil,

L V Prasad Eye Institute, India

Visanee Tantisevi,

Chulalongkorn University, Thailand

*Correspondence:

Yingting Zhu

zhuyingting@gzzoc.com

Yehong Zhuo

zhuoyh@mail.sysu.edu.cn

Specialty section:

This article was submitted to

Ophthalmology

a section of the journal

Frontiers in Medicine

Received: 12 July 2021 Accepted: 06 September 2021 Published: 11 October 2021

Citation:

Wen Y, Zhu Y and Zhuo Y (2021) Changes of Peripapillary Retinal Nerve Fiber Layer in Childhood Glaucoma: A

Systematic Review and

Meta-Analysis. Front. Med. 8:740152.

doi: 10.3389/fmed.2021.740152

\section{Changes of Peripapillary Retinal Nerve Fiber Layer in Childhood Glaucoma: A Systematic Review and Meta-Analysis}

\author{
Yuwen Wen, Yingting Zhu* and Yehong Zhuo* \\ State Key Laboratory of Ophthalmology, Zhongshan Ophthalmic Center, Sun Yat-sen University, Guangzhou, China
}

Objectives: Retinal nerve fiber layer (RNFL) thickness has been detected by numerous studies about alterations and abnormalities in childhood glaucoma, but these studies have yielded inconsistent results about the RNFL thinning region. The investigation of characteristics of RNFL in pediatric patients would contribute to the deep understanding of the neuropathic mechanisms of childhood glaucoma. Thus, the degree of thinning in different quadrants deserves further discussion and exploration.

Method: A systematic literature search was conducted using the Cochrane Central Register of Controlled Trials, Medline, Embase, and PubMed databases to identify clinical studies published from inception to April 1, 2021.

Results: Ten studies were included in this review with a total of 311 children with glaucoma and 444 in nonglaucomatous controls. The results revealed that average peripapillary RNFL (pRNFL) thickness was attenuated in pediatric patients with glaucoma [weighted mean difference $(\mathrm{WMD})=-20.75 ; 95 \% \mathrm{Cl}-27.49$ to $-14.01 ; p<0.00001$ ]. Additionally, pRNFL thickness in eight quadrants (superior, inferior, temporal, nasal, superotemporal, inferotemporal, superonasal, and inferonasal) had different levels of reduction in the pediatric group of glaucoma.

Conclusion: This study indicates that eight regions of RNFL thickness show various degrees of thinning in childhood glaucoma. However, caution is required in the interpretation of results due to marked heterogeneity. Future studies, especially larger samples and multicenter, need to confirm our results.

Keywords: childhood glaucoma, retinal nerve fiber layer (RNFL) thickness, glaucoma optic nerve damage, spectral-domain optical coherence tomography (SD-OCT), meta-analysis

\section{INTRODUCTION}

Glaucoma is a multifactorial, progressive optic neuropathy with unclear pathogenesis characterized by visual field deficits and cupping of the optic nerve (1-3). As a major cause of irreversible blindness, more than 70 million people worldwide are affected and approximately $10 \%$ of the patients with glaucoma are bilaterally blind $(4,5)$. Childhood glaucoma is a varied group of disorders occurring in children and adolescents younger than 16 years that requires careful attention to prevent vision loss throughout life. It is 
estimated that $5 \%$ of blindness in children worldwide is caused by childhood glaucoma (6). Primary congenital glaucoma (PCG) is the most common type of childhood glaucoma accounting for $32-47 \%(7,8)$ and $70-80 \%$ of cases are bilateral $(9,10)$. Most of the patients with childhood glaucoma present within 6 months of birth with $\sim 80 \%$ appearing before 1 year of age (11). Childhood glaucoma and its management not only have a marked impact on functional vision of children, but also reduced the quality of life of the patients, relatives, and caregivers (12-14). Hence, early diagnosis is crucial for children affected with glaucoma to receive timely and appropriate treatment.

The clinical visual field is regarded as the essential part of following-up and identifying neurological damage and progressive change in glaucoma. However, visual field testing in children is limited. Different from the adult patients, children have shortened duration for maintaining attention and learning curve, which requires correctly explaining the visual field findings $(15,16)$. The measurement of intraocular pressure (IOP) is another essential part of the diagnosis and follow-up of glaucoma. However, this detection of young children often has large fluctuation due to poor cooperation.

The pathological changes in glaucoma include cupping of the optic disk, thinning of the retinal nerve fiber layer (RNFL), and loss of the retinal ganglion cells $(3,17,18)$. Recently, detection of glaucomatous structural changes has relied on the assessment of morphological changes within fundus photography or direct ophthalmoscopes such as cup-to-disk ratio (CDR) and bilateral asymmetry. A well-known phenomenon in pediatric glaucoma is that cupping of the optic disk can be reversible after remarkable IOP reduction, especially before 1 year of age (19-21). However, cupping reversal in childhood glaucoma may not be a good indicator to assess the improvement of optic nerve head health. Continued RNFL thinning was observed in some cases with IOP reduction and cupping reversal after treatment of glaucoma (22). Preoperative RNFL thickness is a key prognostic indicator of RNFL thinning progress even after surgery and visual prognosis. A precise evaluation of the RNFL is crucial for diagnosing and monitoring pediatric glaucoma.

With the appearance of spectral-domain optical coherence tomography (SD-OCT), it is possible to monitor the automatic segmentation of the individual retinal layers. It has been widely used in the diagnosis and follow-up of glaucoma in recent years. Being a simple, non-invasive, and safe imaging test, it has been intensely applied to measure and observe the change in the peripapillary retinal nerve fiber layer ( $\mathrm{pRNFL}$ ) (23). SD-OCT has dramatically improved image resolution and reliably detects glaucoma disease and progression in adults (24). Considering the difficulty of testing children, the most recent SD-OCT is designed to handheld OCT or overhead mounted OCT to make infants and young children benefit from this technology.

Recently, several studies using SD-OCT were performed to compare pRNFL thickness in children with glaucoma and healthy children and to convey conflicting results. Some researchers have reported the thinning of average pRNFL thickness in all sectors between pediatric glaucoma and controls (25-30). However, other studies have found that children with glaucoma and normal participants have comparable pRNFL thickness in some regions such as the temporal, nasal, and inferior nasal quadrants (31-34). Thus, the possible association of each sector between pRNFL thickness and childhood glaucoma remains unclear, which justifies the need for more studies on this issue. In this meta-analysis, we aimed to carry out a comprehensive overview of the characteristics of thinning RNFL in childhood glaucoma offered by SD-OCT applications. Furthermore, by analyzing the average eight quadrants of pRNFL thickness changes in pediatric glaucoma compared with the normal participants, we can investigate whether pRNFL thickness measurements are affected in childhood glaucoma and whether they could provide a diagnostic tool in assessing pediatric patients as in adults. Finally, this study also summarized similarities and differences of RNFL thickness between children and adults and the role of SD-OCT in childhood glaucoma.

\section{MATERIALS AND METHODS}

This review was conducted and reported according to the guidelines presented by the PRISMA statements and the MetaAnalyses and Systematic Reviews of Observational Studies statement $(35,36)$.

\section{Literature Search}

We searched Cochrane Central Register of Controlled Trials, Medline, Embase, and PubMed from database inception to April 1, 2021, with keywords: "childhood glaucoma," "pediatric glaucoma," "juvenile glaucoma," "retinal nerve fiber layer," "RNFL," "spectral-domain optical coherence tomography," and "SD-OCT." Manual searching of reference lists from all relevant retrieved articles was conducted to identify additional eligible studies. Eligible papers were screened by two authors independently and the duplicated and irrelevant studies were removed. After screening the abstracts, the remaining articles were checked by full-text review.

\section{Inclusion and Exclusion Criteria}

We enrolled the studies if all the inclusion criteria and no exclusion criteria were met as follows. The relative search and selection were shown as a flowchart (Figure 1).

In our meta-analysis, the inclusion criteria were (1) original articles reporting independent studies; (2) images with satisfactory quality that measured RNFL thickness by using SD-OCT; (3) satisfactory SD-OCT scan quality recorded in the article; (4) clinical trial, prospective or retrospective cross-sectional study, or case-control study; (5) comparison of pediatric patients with glaucoma and healthy controls or physiologic cupping controls; and (6) sample size $\geq 10$ in each group. Moreover, studies were excluded if they met the following criteria: (1) the study groups were adult patients (aged 16 years or older); (2) RNFL thickness was not measured by SD-OCT; (3) reviews, letters, case reports, and studies with important data unavailable; and (4) studies without the healthy control group.

\section{Data Extraction}

The following information contained in all the eligible publications was retrieved independently by two authors: 


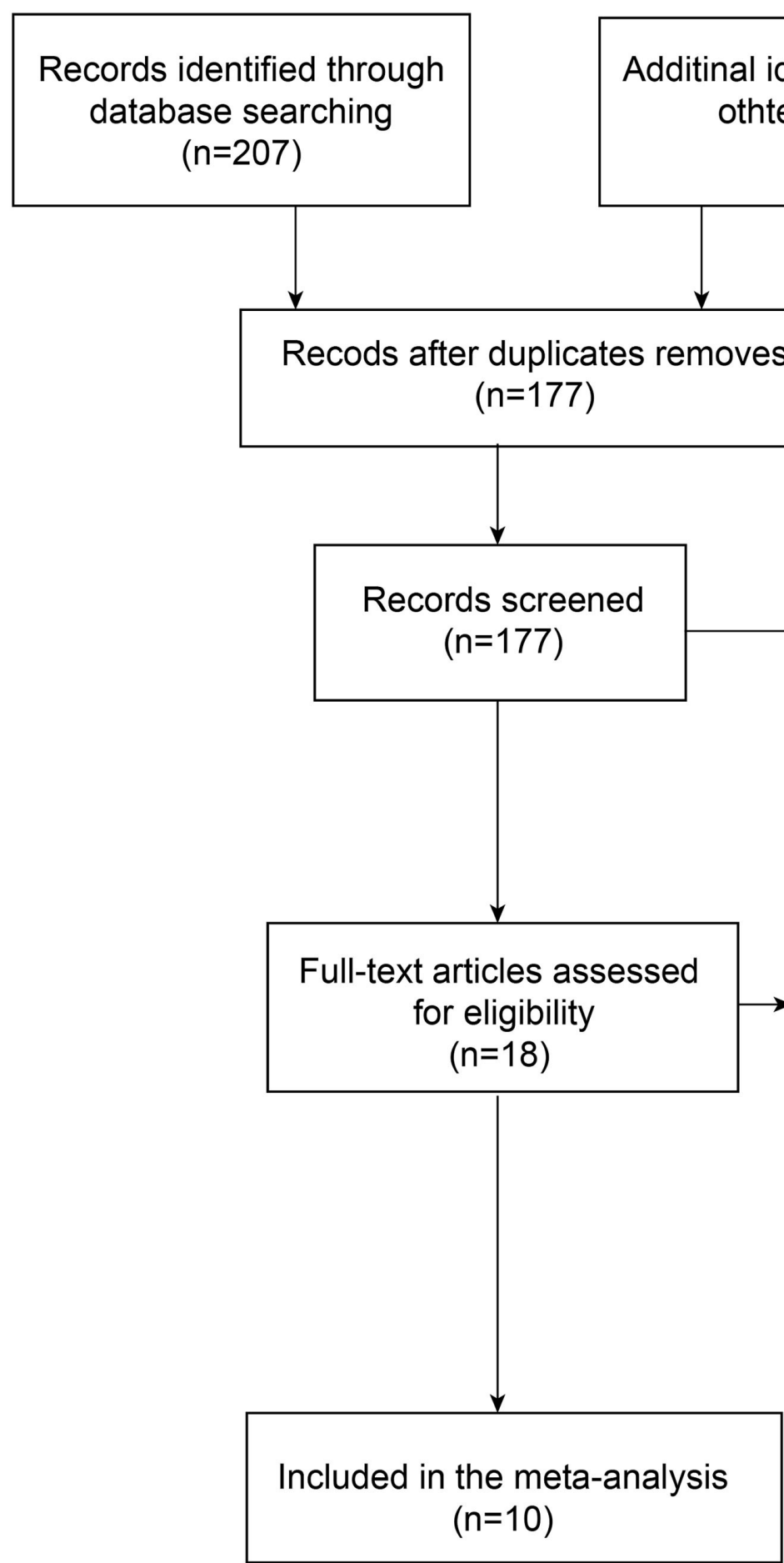

FIGURE 1 | Flowchart of study selection.

first author, country, year of publication, study type, SD-OCT manufacturer, glaucoma type, mean age, gender, CDR, number of participations, IOP, and average eight quadrants of pRNFL thickness. Discrepancies in data extraction were solved by discussion or by consulting the third author. Projecting a circle of $3.5 \mathrm{~mm}$ in diameter on the retina and divided into eight sectors totaling $360^{\circ}$. The pRNFL thickness parameters evaluated in these studies were average thickness $\left(360^{\circ}\right.$ measurement), superior quadrant thickness $\left(46^{\circ}-135^{\circ}\right.$ including $45^{\circ}$ superonasal sector and $45^{\circ}$ superotemporal sector), inferior quadrant 
thickness $\left(226-315^{\circ}\right.$ including $45^{\circ}$ inferonasal sector and $45^{\circ}$ inferotemporal sector), nasal quadrant thickness $\left(136-225^{\circ}\right)$, and temporal quadrant thickness $\left(316-45^{\circ}\right)$.

\section{Quality Assessment}

The Newcastle-Ottawa Scale (NOS) was used to assess the methodological quality of all the included studies. The NOS is a star system to judge quality based on three elements of a study: selection, comparability, and outcome or exposure. The maximum NOS score is nine and the study with a NOS score of $\geq 6$ was considered to be of relatively high quality. Quality was assessed independently by the two reviewers and disagreements were resolved via discussion.

\section{Statistical Analysis}

We used Review Manager version 5.3 to perform the metaanalyses. The data of RNFL thickness were entered as a continuous variable. Means and standard deviations (SDs) were used to calculate the weighted mean differences (WMDs) for continuous outcomes. A $p<0.05(p<0.05)$ was regarded as the criterion for statistical significance. Substantial heterogeneity was defined as 12 values of more than $50 \%$. We adopted a fixed effects model for analysis if there was no heterogeneity across studies ( $p$ $>0.1, \mathrm{I} 2<50 \%)$. Otherwise, a random effects model was used (DerSimonian and Kacker). The potential publication bias was evaluated by funnel plot and Egger's statistics.

\section{RESULTS}

\section{Selection of Studies}

The literature screening strategy was summarized and presented by a flowchart (Figure 1). In total, 207 pieces of literature were initially identified via the original search and 30 pieces were excluded due to duplication. In addition, 18 publications were left for further evaluation after screening titles and abstracts. Out of these reports, eight pieces could not provide useful or available data for meta-analysis. Thus, we excluded these publications that did not meet the inclusion criteria. Finally, a total of 10 studies, consisting of 311 patients with glaucoma and 444 controls, were included in the meta-analysis.

\section{Characteristics and Quality Assessment of the Studies}

During the enrollment period, a total of 755 participants (311 in the glaucoma group and 444 in the control group) were included in our meta-analysis. Six studies were performed in the USA and the other four studies were performed in the UK, Spain, India, and Germany. The characteristics and qualities of these studies are shown in Table 1.

\section{Meta-Analysis of Childhood Glaucoma Group Compared With a Healthy Control Group}

Analysis of average pRNFL thickness between the group of children with glaucoma and children without glaucoma in eight studies showed significant heterogeneity (I2 = 89\%). Hence, the random effects model was used for data analysis. The meta-analysis showed that the average pRNFL thickness in the pediatric glaucoma group was decreased significantly than the non-glaucomatous group (WMD $=-20.75$; 95\% CI -27.49$-14.01 ; p<0.00001$, Figure 2).

In addition, we also examined the difference in pRNFL thickness between patients with glaucoma and healthy controls in each quadrant and there was significant difference in pRNFL thickness between those two groups in the superior (WMD = -30.80 ; $95 \% \mathrm{CI}-47.00$ to $-14.59 ; p<0.00001$ ), inferior (WMD $=-31.81 ; 95 \% \mathrm{CI}-46.04$ to $-17.58 ; p<0.00001)$, nasal (WMD $=-11.61 ; 95 \% \mathrm{CI}-17.21$ to $-6.02 ; p<0.00001)$, temporal $(\mathrm{WMD}=-10.07 ; 95 \% \mathrm{CI}-14.84$ to $-5.30 ; p<0.00001)$, superotemporal $(\mathrm{WMD}=-34.71 ; 95 \% \mathrm{CI}-47.52$ to $-21.90 ; p=$ 0.03 ), inferotemporal (WMD $=-22.44 ; 95 \% \mathrm{CI}-43.26$ to -1.61 ; $p=0.002$ ), inferonasal (WMD $=-26.45$; $95 \% \mathrm{CI}-38.59$ to $-14.30 ; p=0.03$ ), and superonasal quadrant (WMD $=-24.99$; $95 \% \mathrm{CI}-37.04$ to $-12.93 ; p=0.04$ ) between the glaucoma group and healthy control (Figure 3 ).

\section{Publication Bias}

Due to the few eligible studies in our meta-analysis, funnel plots were easily seen as asymmetrical and we could not claim or deny bias for certain. Therefore, the funnel plot and Egger's statistics were not interpretable (data are not shown).

\section{DISCUSSION}

To the best of our knowledge, this review and metaanalysis are the first systematic synthesizing currently available observational studies to investigate the pRNFL thickness in childhood glaucoma. In this comprehensive meta-analysis, we investigated the specific regions of reduced pRNFL thickness in childhood glaucoma. As expected, the average pRNFL thickness was significantly thinner in the pediatric patients with glaucoma than in the healthy controls. There were also significant differences in pRNFL thickness between the groups in the superior, inferior, nasal, temporal, superotemporal, inferotemporal, superonasal, and inferonasal quadrants. We additionally observed the tendency of pRNFL thinning among the different regions in pediatric glaucoma of which the nasal and temporal quadrants demonstrated a small reduction in pRNFL thickness. The present meta-analysis showed that childhood glaucoma is strongly associated with changes in pRNFL thickness in the peripapillary region.

In our view, one of the important sources of high heterogeneity may have been the different inclusion criteria and adjusted factors across the studies. First, there were differences in types of childhood glaucoma and only the two pieces of literature mentioned the severity of glaucoma. Second, the exclusion criteria of individual studies differed greatly. For example, one study excluded patients with juvenile open-angle glaucoma (JOAG) that was considered an inherently progressive disease, while others included them or did not state whether JOAG was included. Additionally, the age range of childhood glaucoma was large, which may be a confounding variable in heterogeneity analysis. Third, although the pooled results of our study showed a significant decrease in superior, inferior, and 
TABLE 1 | Characteristics of included studies.

\begin{tabular}{|c|c|c|c|c|c|c|c|c|c|c|c|c|c|c|c|}
\hline \multirow{2}{*}{ Reference } & \multirow[t]{2}{*}{ Country } & \multirow{2}{*}{$\begin{array}{l}\text { Study } \\
\text { type }\end{array}$} & \multirow{2}{*}{$\begin{array}{l}\text { SD-OCT } \\
\text { brand }\end{array}$} & \multirow[t]{2}{*}{ Glaucoma } & \multicolumn{2}{|c|}{ No. of participants } & \multicolumn{2}{|c|}{ Gender (Male) } & \multicolumn{2}{|c|}{ Age $(Y)$, mean \pm SD } & \multicolumn{2}{|c|}{$\mathrm{CDR}$, mean $\pm \mathrm{SD}$} & \multicolumn{2}{|c|}{ IOP (mm Hg) } & \multirow{2}{*}{$\begin{array}{l}\text { Quality } \\
\text { scaling } \\
\text { (NOS) }\end{array}$} \\
\hline & & & & & Case & Control & Case & Control & Case & Control & Case & Control & Case & Control & \\
\hline $\begin{array}{l}\text { Lever et al. } \\
\text { (34) }\end{array}$ & Germany & 3 & $\begin{array}{l}\text { Heidelberg } \\
\text { spectralis }\end{array}$ & $\begin{array}{l}\text { PCG, } \\
\text { JOAG, } \\
\text { other } \\
\text { types }\end{array}$ & 19 & 53 & NA & NA & $11.2 \pm 3.5$ & $12.2 \pm 3.5$ & 0.8 & 0.6 & $\begin{array}{c}18.7 \pm \\
7.2\end{array}$ & $\begin{array}{c}14.5 \pm \\
2.7\end{array}$ & 7 \\
\hline $\begin{array}{l}\text { Michelle et al. } \\
\text { (31) }\end{array}$ & USA & 1 & $\begin{array}{l}\text { Heidelberg } \\
\text { spectralis }\end{array}$ & $\mathrm{G} / \mathrm{SG}$ & 39 & 57 & 22 & 28 & $5.9 \pm 5.9$ & $2.3 \pm 1.5$ & NA & NA & $23 \pm 8$ & $14 \pm 3$ & 7 \\
\hline $\begin{array}{l}\text { Perucho- } \\
\text { González et } \\
\text { al. (32) }\end{array}$ & USA & 2 & $\begin{array}{l}\text { Heidelberg } \\
\text { spectralis }\end{array}$ & PCG & 59 & 87 & NA & NA & $9.61 \pm 3.23$ & $8.47 \pm 2.99$ & NA & NA & $\begin{array}{c}19.11 \pm \\
4.23\end{array}$ & $\begin{array}{c}13.95 \pm \\
1.98\end{array}$ & 6 \\
\hline Pilat et al. (33) & UK & 2 & $\begin{array}{l}\text { Envisu } \\
2,300\end{array}$ & PCG & 20 & 20 & 10 & 11 & $4.64 \pm 2.79$ & $4.73 \pm 2.81$ & $0.668 \pm 0.173$ & $0.398 \pm 0.178$ & $\begin{array}{c}17.68 \pm \\
6.52\end{array}$ & NA & 8 \\
\hline Xu et al. (30) & USA & 3 & $\begin{array}{l}\text { Heidelberg } \\
\text { spectralis }\end{array}$ & PCG & 20 & 15 & 11 & 6 & $9.7 \pm 3.3$ & $11.2 \pm 3.3$ & $0.4 \pm 0.2$ & $0.7 \pm 0.1$ & $\begin{array}{c}15.4 \pm \\
3.6\end{array}$ & $\begin{array}{c}16.5 \pm \\
3.6\end{array}$ & 8 \\
\hline $\begin{array}{l}\text { Morales- } \\
\text { Fernandez et } \\
\text { al. (27) }\end{array}$ & Spain & 2 & $\begin{array}{l}\text { Heidelberg } \\
\text { spectralis }\end{array}$ & PCG & 40 & 60 & 24 & 24 & $11.20 \pm 3.94$ & $10.90 \pm 2.46$ & $0.52 \pm 0.29$ & $0.24 \pm 0.14$ & NA & NA & 7 \\
\hline $\begin{array}{l}\text { Silverstein et } \\
\text { al. (28) }\end{array}$ & USA & NA & $\begin{array}{l}\text { Heidelberg } \\
\text { spectralis }\end{array}$ & $\begin{array}{l}\text { PCG/ } \\
\text { JOAG }\end{array}$ & 37 & 43 & 20 & 22 & $\begin{array}{c}9.9 \pm 3.3(\mathrm{PCG}) \\
13.1 \pm \\
2.0(\mathrm{JOAG})\end{array}$ & $\begin{array}{c}11.1 \pm 3.1 \\
(\mathrm{PC}) \\
12.3 \pm 3.2(\mathrm{~N})\end{array}$ & $\begin{array}{c}0.52 \pm \\
0.29 \text { (PCG) } \\
0.83 \pm \\
0.2 \text { (JOAG) }\end{array}$ & $\begin{array}{c}0.7 \pm 0.11 \\
(P C G) \\
0.21 \pm 0.12\end{array}$ & NA & NA & 6 \\
\hline $\begin{array}{l}\text { Ghasia et al. } \\
\text { (26) }\end{array}$ & USA & 1 & $\begin{array}{l}\text { Optovue } \\
\text { RTVue }\end{array}$ & $\mathrm{G} / \mathrm{SG}$ & 12 & 13 & 6 & 6 & $11.5 \pm 3.5$ & $10 \pm 2.5$ & $0.4 \pm 0.2$ & $0.1 \pm 0.1$ & NA & NA & 8 \\
\hline $\begin{array}{l}\text { Srinivasan et } \\
\text { al. (29) }\end{array}$ & India & 4 & $\begin{array}{l}\text { Heidelberg } \\
\text { spectralis }\end{array}$ & PCG & 37 & 41 & 20 & 22 & $10.1 \pm 3.6$ & $13.6 \pm 3.2$ & NA & NA & $\begin{array}{c}30.2 \pm \\
5.9\end{array}$ & NA & 8 \\
\hline $\begin{array}{l}\text { Ghasia et al. } \\
\text { (25) }\end{array}$ & USA & 1 & $\begin{array}{l}\text { Heidelberg } \\
\text { spectralis }\end{array}$ & $\begin{array}{l}\text { MG/M- } \\
\text { to-SG }\end{array}$ & 28 & 55 & 15 & 30 & $\begin{array}{c}12 \pm 1.08 \text { (MG) } \\
13 \pm \\
1.6 \text { (M-to-SG) }\end{array}$ & $\begin{array}{c}11 \pm 0.75 \\
(\mathrm{PC}) \\
12 \pm 3(\mathrm{~N})\end{array}$ & $\begin{array}{c}0.43 \pm 0.04 \\
(\mathrm{MG}) \\
0.72 \pm \\
0.04 \text { (M-to-SG) }\end{array}$ & $\begin{array}{c}0.67 \pm 0.02 \\
(\mathrm{PC}) \\
0.15 \pm 0.03(\mathrm{~N})\end{array}$ & NA & NA & 7 \\
\hline
\end{tabular}

1, Prospective cross-sectional study; 2, Observational cross-sectional study; 3, Retrospective observational case series; 4, Case-control study. OCT, optical coherence tomography; G, glaucoma; SG, suspect glaucoma; PCG, primary congenital glaucoma; JOAG, juvenile open-angle glaucoma; MG, mild glaucoma; $M$-to-SG, moderate-to-severe glaucoma; PC, physiologic cupping; N, normal; NA, not available; CDR, cup-to-disc ratio; IOP, intraocular pressure. 


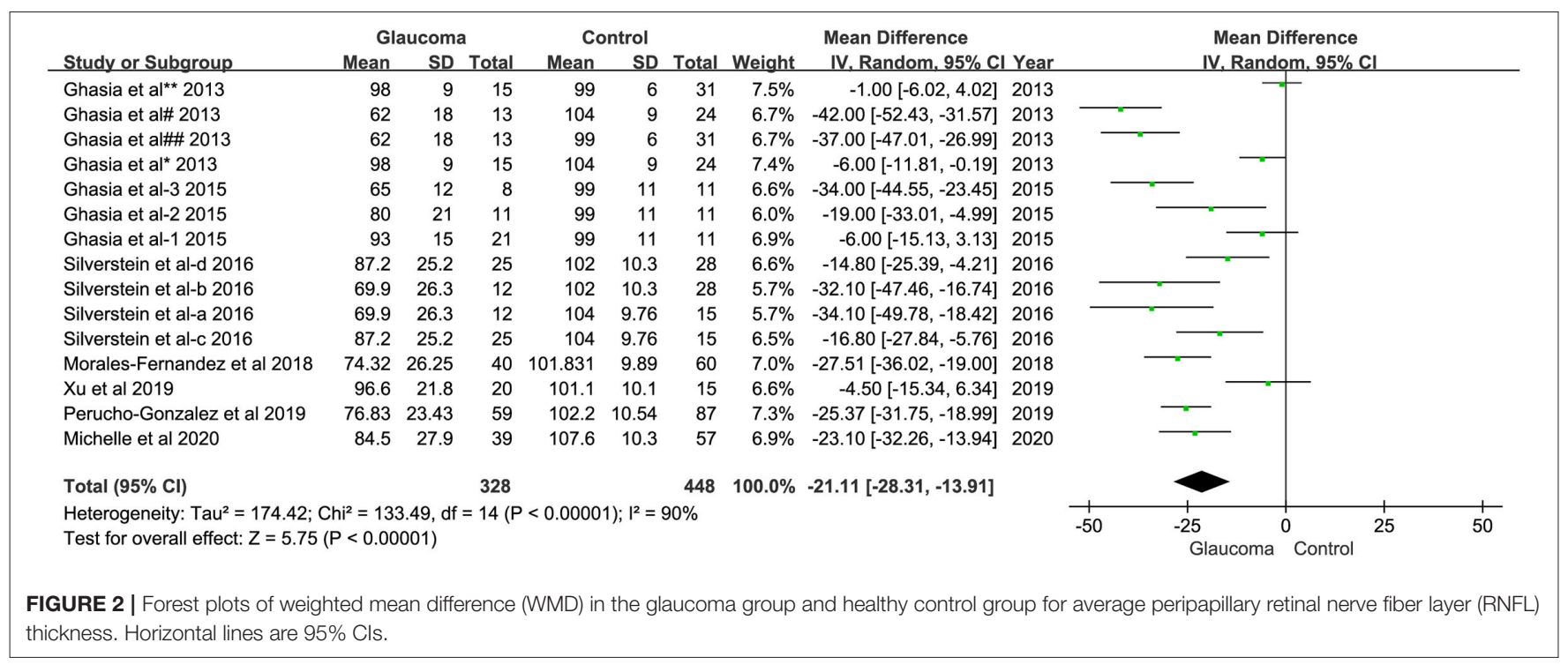

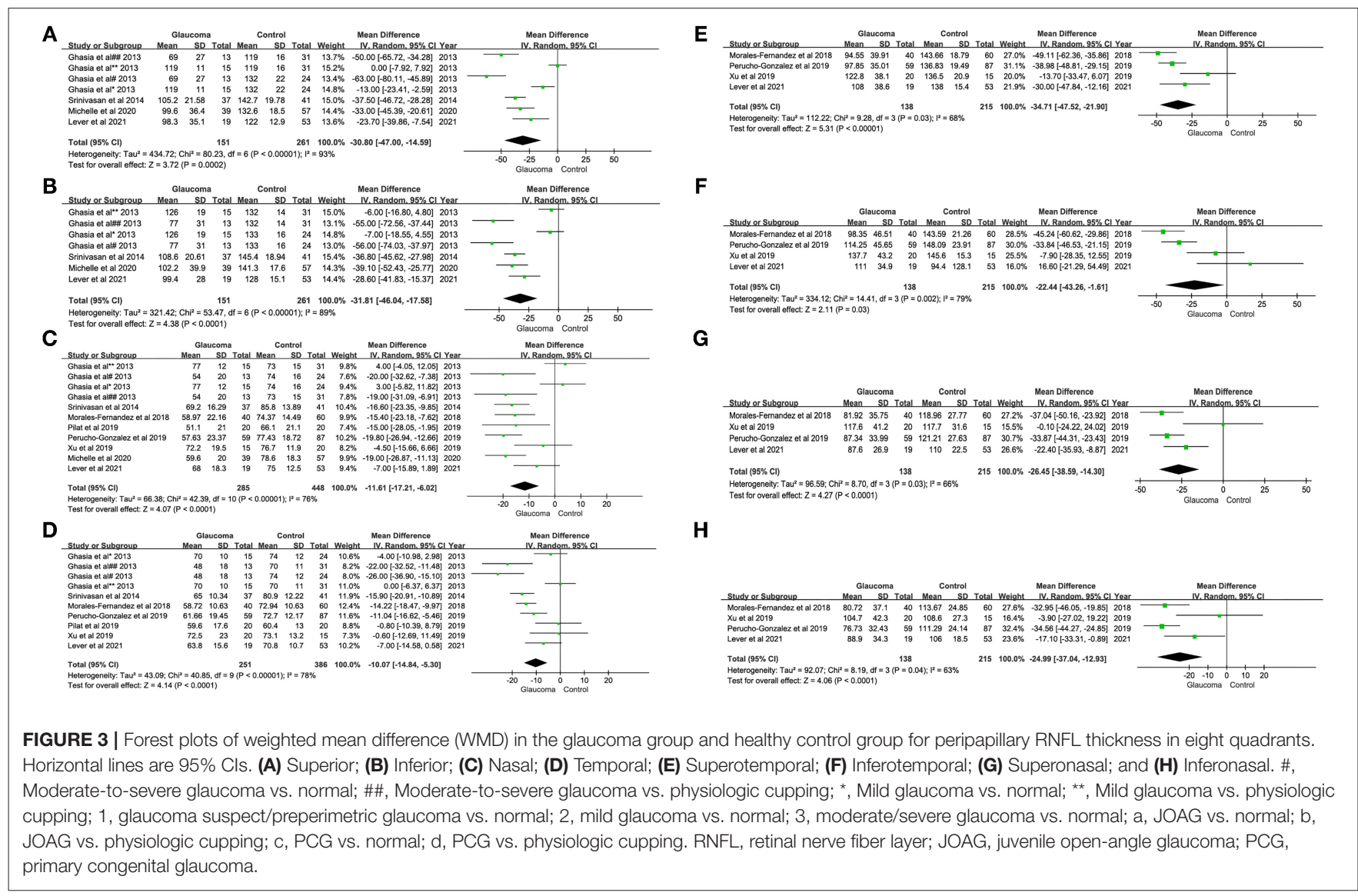

superotemporal quadrants, we could not speculate which regions had the most significant reduction in children with glaucoma due to a large $95 \% \mathrm{CI}$, which is probably related to the severity of glaucoma.

It is reported that the pRNFL thickness in the superior and inferior quadrants is thicker and the temporal and nasal quadrants are relatively thinner in healthy adults (37-39). Turk et al. (40) evaluated 107 healthy Turkish children aged 6-16 years using SD-OCT and found that the average pRNFL thickness was $106.45 \pm 9.41 \mu \mathrm{m}$, inferotemporal pRNFL (the thickest sector) thickness was $144.64 \pm 17.16 \mu \mathrm{m}$, and nasal pRNFL (the thinnest sector) thickness was $71.54 \pm 10.03 \mu \mathrm{m}$. Zhu et al. (41) examined 
2,105 12-year-old healthy students using SD-OCT and reported that the average pRNFL thickness was $103.08 \pm 1.2 \mu \mathrm{m}$ and the pRNFL thickness was thicker with shorter axial length and higher hyperopia. Rotruck et al. (42) reported that the mean global pRNFL thickness of healthy children aged 0-5 years old was $107.6 \pm 10.3 \mu \mathrm{m}$ and it was not dependent on age. In general, the thickest region of pRNFL in healthy children is the inferior quadrant, which is thicker than in adults and not dependent on age but showed a negative relationship with axial length (4144). The pRNFL thickness may attenuate subsequently because of physiologic growth in axial length during the growth and development of children. However, this corresponding change of normal eyes in pRNFL thickness is considerably less than the variability compared with pathological progression and should not be clinically significant $(30,45)$. Moreover, children with large CDRs were considered as the potential hazard of a glaucomatous process. However, the study (46) revealed that the degree of optic nerve cupping does not correlate with the RNFL thickness. Normal eyes and physiologic cupping showed equivalence in the several measurement parameters between all macular layers and pRNFL (28). Hence, the data can be analyzed by incorporating both normal controls and physiologic cupping simultaneously.

More attention should be given when the pRNFL thickness thinning exceeds approximately $8 \mu \mathrm{m}$ because it is a likely sign of the probable clinical change (30). Compared to the other optic disc parameters, pRNFL thickness has a higher diagnostic accuracy of glaucoma, especially in the superior and inferior regions $(27,47)$. Studies have shown that RNFL thinning commonly begins with the inferior and superior sectors and then affects nasal and temporal regions in adult patients and the temporal RNFL quadrant is most conserved in glaucoma $(48,49)$. This phenomenon may be explained by the preservation of central vision in patients with glaucoma, which is mainly fed by the temporal RNFL fibers (50-52). The changes of pRNFL thickness are meaningful in these children with less severe glaucomatous optic nerve damage, where the damage of visual function may be difficult to measure. Thus, the superior and inferior pRNFL might be optimal to reflect glaucomatous changes, which is consistent with the results of our meta-analysis. In the adult patients with pseudoexfoliation glaucoma, one of the subtypes of open-angle glaucoma, the temporal RNFL thickness is not significantly different from the healthy controls. Our results, however, showed otherwise. In our meta-analysis, the temporal pRNFL thickness was thinning but the superonasal sectors were not different from normal eyes (48). This indicates that childhood glaucoma has its characteristics of RNFL thinning. Furthermore, a larger lamina cribrosa curvature index (LCCI) was perceived as the first indication of prognosis for faster progressive RNFL thinning. Primary congenital glaucoma (PCG) had significantly deeper cups than adults with primary open angle glaucoma emphasizing the importance of measuring cup depth besides concerning $\operatorname{CDR}(53,54)$. Therefore, additional research is needed to demonstrate these differences with the development and preservation of visual function in childhood glaucoma and glaucoma in adults. Our focus should be especially on cup depth and morphology of lamina cribrosa testing
RNFL thinning by SD-OCT in pediatric patients. Some of the included studies elucidated the stage of glaucoma $(25,26)$ and others were not (27-33), which may influence our metaanalysis of RNFL thickness. These could explain the high degree of statistical heterogeneity between the studies in the metaanalysis.

Spectral domain optical coherence tomography is a valuable tool in diagnosing and monitoring visual loss, especially for pediatric glaucoma. It provides an objective and quantitative scan with three-dimensional images, increased speed of image acquisition, and improved axial resolution for early diagnosis and monitoring of disease progression. This device has proved to be useful in the management of pediatric glaucoma as it provides objective RNFL thickness measurements in children (45). The advantages of SD-OCT compared to OCT devices in the past are short exposure durations and automatic eyetracking systems. SD-OCT has higher sensitivity and specificity compared to the past OCT devices in detecting RNFL thickness. Its overall diagnostic precision of detecting and measuring localized RNFL defects in patients with glaucoma was also relatively higher than conventional fundus photographs (55, 56). Consequently, SD-OCT has potential clinical value in evaluating progression and follow-up for pediatric glaucoma as an effective means.

However, it was challenging to obtain high-quality images for children with glaucoma in the past due to poor cooperation, the opacity of refractive media, and unsuitable examination equipment. Poor-quality images often make it difficult for ophthalmologists to judge the progression of the disease. Delaying in diagnosis and treatment can increase the risk of irreversible optic nerve damage and even blindness. With the technical improvement and development of new instruments, the emergence of handheld OCT and overhead-mounted OCT solved this problem perfectly. The high-quality image can be acquired and analyzed by handheld and overhead-mounted OCT in very young patients. Updated SD-OCT has presented benefits for improved clinical management and study of the pathophysiology associated with childhood glaucoma $(31,33)$.

To some extent, there were several limitations to this study that need to be considered. First, the number of included studies as well as the included pediatric patients with glaucoma in each study was relatively small. In addition, childhood glaucoma is rare and there are some limitations to acquire good-quality imaging such as nystagmus or poor media opacity. Second, the severity of glaucoma was verified to be related to the mean pRNFL global thickness in children older than 6 years $(40,44)$, but we were unable to analyze the association between pRNFL thickness and the severity of pediatric glaucoma due to lack of sufficient studies providing data on the severity of glaucoma. Third, included studies of this meta-analysis were applied in four different SD-OCT devices (8 Heidelberg, 1 Envisu, and 1 Optovue). A primary concern was the measurement differences between manufacturers, which were statistically significant in the past and the clinical implication of this difference is less clear (57). However, this study believed that there were no statistically 
significant differences between devices for any particular area imaged and no major differences were noted for any of the parameters across OCT devices (58). Fourth, as a non-negligible factor, axial length affects RNFL measurement in the direction of thinner RNFL because of physiological growth or pathological factors such as high myopia (59). Therefore, future studies should obtain a random distribution of myopic and non-myopic participants in both normal and glaucomatous subgroups. Fifth, although, we had demonstrated specific regions of thinning pRNFL in pediatric glaucoma, the lack of studies about earlystage changes and progression in childhood glaucoma is a current limitation.

\section{CONCLUSION}

In summary, our meta-analysis indicates that patients with childhood glaucoma have significantly reduced average eight quadrants RNFL thickness compared with healthy controls. We also observed a non-uniformity in the thinning of the pRNFL in different quadrants. Therefore, we suggest that the segmentation of peripapillary RNFL thickness as measured by $\mathrm{SD}-\mathrm{OCT}$ can provide valuable information for the diagnosis and follow-up of childhood glaucoma. Moreover, a standardized and reproducible measurement technique of RNFL thickness needs to be introduced and utilized in children. In future research, further studies with multicenter and larger sample sizes, prospective and longitudinal studies are required to confirm the present results of this meta-analysis.

\section{REFERENCES}

1. Flaxman SR, Bourne R, Resnikoff S, Ackland P, Braithwaite T, Cicinelli $\mathrm{MV}$, et al. Global causes of blindness and distance vision impairment 19902020: a systematic review and meta-analysis. Lancet Glob Health. (2017) 5:e1221-34. doi: 10.1016/S2214-109X(17)30393-5

2. Bourne R, Flaxman SR, Braithwaite T, Cicinelli MV, Das A, Jonas $\mathrm{JB}$, et al. Magnitude, temporal trends, and projections of the global prevalence of blindness and distance and near vision impairment: a systematic review and meta-analysis. Lancet Glob Health. (2017) 5:e888-97. doi: 10.1016/S2214-109X(17)30293-0

3. Jonas JB, Aung T, Bourne RR, Bron AM, Ritch R, Panda-Jonas S. Glaucoma. Lancet. (2017) 390:2183-93. doi: 10.1016/S0140-6736(17)31469-1

4. Weinreb RN, Aung T, Medeiros FA. The pathophysiology and treatment of glaucoma: a review. JAMA. (2014) 311:1901-11. doi: 10.1001/jama.2014.3192

5. Quigley HA, Broman AT. The number of people with glaucoma worldwide in 2010 and 2020. Br J Ophthalmol. (2006) 90:2627. doi: 10.1136/bjo.2005.081224

6. Gilbert C, Rahi J, West K. Visual impairment and blindness in children. In: Johnson GJ, Minassian DC, Weale RA, West SK, editors. The Epidemiology of Eye Disease. 3rd ed. London: Imperial College Press (2012). p. 267-368.

7. Hoguet A, Grajewski A, Hodapp E, Chang TC. A retrospective survey of childhood glaucoma prevalence according to childhood glaucoma research network classification. Indian J Ophthalmol. (2016) 64:118-23. doi: 10.4103/0301-4738.179716

8. Ben-Zion I, Tomkins O, Moore DB, Helveston EM. Surgical results in the management of advanced primary congenital glaucoma in a rural pediatric population. Ophthalmology. (2011) 118:231-5. doi: 10.1016/j.ophtha.2010.02.027

\section{DATA AVAILABILITY STATEMENT}

The original contributions presented in the study are included in the article/supplementary material, further inquiries can be directed to the corresponding author/s.

\section{AUTHOR CONTRIBUTIONS}

YW was responsible for designing the review protocol, writing the protocol and report, conducting the search, screening potentially eligible studies, extracting and analyzing data, interpreting results, updating reference lists, and creating figures and tables. YiZ was responsible for designing the review protocol and screening potentially eligible studies and contributed to writing the report, extracting and analyzing data, and interpreting results. YeZ contributed to the design of the review protocol, arbitrating potentially eligible studies, extracting and analyzing data, and interpreting results provided feedback on the report. All authors listed have made a substantial, direct and intellectual contribution to the work, and approved it for publication.

\section{FUNDING}

This study was supported by the National Key Research and Development Project of China (grant number 2020YFA0112701) and the National Natural Science Foundation of China (81700858 and 81870658).

9. François J. Congenital glaucoma and its inheritance. Ophthalmologica. (1980) 181:61-73. doi: 10.1159/000309028

10. Franks W, Taylor D. Congenital glaucoma-a preventable cause of blindness. Arch Dis Child. (1989) 64:649-50. doi: 10.1136/adc.64.5.649

11. Papadopoulos M, Cable N, Rahi J, Khaw PT. The British infantile and childhood glaucoma (BIG) eye study. Invest Ophthalmol Vis Sci. (2007) 48:4100-6. doi: 10.1167/iovs.06-1350

12. Dahlmann-Noor A, Tailor V, Bunce C, Abou-Rayyah Y, Adams G, Brookes J, et al. Quality of life and functional vision in children with glaucoma. Ophthalmology. (2017) 124:1048-55. doi: 10.1016/j.ophtha.2017. 02.024

13. Gothwal VK, Bharani S, Mandal AK. Impact of surgery on the quality of life of caregivers of children with congenital glaucoma. Ophthalmology. (2016) 123:1161-2. doi: 10.1016/j.ophtha.2015.11.013

14. Zhu Y, Gao J, Li X, Yang Q, Lian Y, Xiao $\mathrm{H}$, et al. Burden, positive aspects, and predictive variables of caregiving: a study of caregivers of patients with pediatric glaucoma. J Ophthalmol. (2019) 2019:6980208. doi: 10.1155/2019/6980208

15. Blumenthal EZ, Haddad A, Horani A, Anteby I. The reliability of frequency-doubling perimetry in young children. Ophthalmology. (2004) 111:435-9. doi: 10.1016/j.ophtha.2003. 06.018

16. Safran AB, Laffi GL, Bullinger A, Viviani P, de Weisse C, Désangles D, et al. Feasibility of automated visual field examination in children between 5 and 8 years of age. Br J Ophthalmol. (1996) 80:515-8. doi: 10.1136/bjo.80. 6.515

17. Burgoyne CF, Morrison JC. The anatomy and pathophysiology of the optic nerve head in glaucoma. J Glaucoma. (2001) 10(Suppl 1):S168. doi: 10.1097/00061198-200110001-00007 
18. Quigley HA, Nickells RW, Kerrigan LA, Pease ME, Thibault DJ, Zack DJ. Retinal ganglion cell death in experimental glaucoma and after axotomy occurs by apoptosis. Invest Ophthalmol Vis Sci. (1995) 36:774-86.

19. Harju M, Saari J, Kurvinen L, Vesti E. Reversal of optic disc cupping in glaucoma. Br J Ophthalmol. (2008) 92:901-5. doi: 10.1136/bjo.2007.135350

20. Lesk MR, Spaeth GL, Azuara-Blanco A, Araujo SV, Katz LJ, Terebuh AK, et al. Reversal of optic disc cupping after glaucoma surgery analyzed with a scanning laser tomograph. Ophthalmology. (1999) 106:10138. doi: 10.1016/S0161-6420(99)00526-6

21. Azuara-Blanco A, Spaeth GL. Methods to objectify reversibility of glaucomatous cupping. Curr Opin Ophthalmol. (1997) 8:50-4. doi: 10.1097/00055735-199704000-00009

22. Ely AL, El-Dairi MA, Freedman SF. Cupping reversal in pediatric glaucomaevaluation of the retinal nerve fiber layer and visual field. Am J Ophthalmol. (2014) 158:905-15. doi: 10.1016/j.ajo.2014.07.030

23. Budenz DL, Anderson DR, Varma R, Schuman J, Cantor L, Savell J, et al. Determinants of normal retinal nerve fiber layer thickness measured by stratus OCT. Ophthalmology. (2007) 114:1046-52. doi: 10.1016/j.ophtha.2006.08.046

24. Puzyeyeva O, Lam WC, Flanagan JG, Brent MH, Devenyi RG, Mandelcorn MS, et al. High-resolution optical coherence tomography retinal imaging: a case series illustrating potential and limitations. J Ophthalmol. (2011) 2011:764183. doi: 10.1155/2011/764183

25. Ghasia FF, Freedman SF, Rajani A, Holgado S, Asrani S, ElDairi M. Optical coherence tomography in paediatric glaucoma: time domain versus spectral domain. $\mathrm{Br} J$ Ophthalmol. (2013) 97:837-42. doi: 10.1136/bjophthalmol-2012-302648

26. Ghasia FF, El-Dairi M, Freedman SF, Rajani A, Asrani S. Reproducibility of spectral-domain optical coherence tomography measurements in adult and pediatric glaucoma. J Glaucoma. (2015) 24:55-63. doi: 10.1097/IJG.0b013e31829521db

27. Morales-Fernandez L, Jimenez-Santos M. Martinez-de-la-Casa JM, Sanchez-Jean R, Nieves M, Saenz-Frances F, et al. Diagnostic capacity of SD-OCT segmented ganglion cell complex versus retinal nerve fiber layer analysis for congenital glaucoma. Eye. (2018) 32:1338-44. doi: 10.1038/s41433-018-0077-4

28. Silverstein E, Freedman S, Zéhil G, Jiramongkolchai K, El-Dairi M. The macula in pediatric glaucoma: quantifying the inner and outer layers via optical coherence tomography automatic segmentation. J AAPOS. (2016) 20:332-6. doi: 10.1016/j.jaapos.2016.05.013

29. Srinivasan S, Addepalli UK, Rao HL, Garudadri CS, Mandal AK. Spectral domain optical coherence tomography in children operated for primary congenital glaucoma. Brit J Ophthalmol. (2014) 98:1625. doi: 10.1136/bjophthalmol-2012-302486

30. Xu L, Freedman SF, Silverstein E, Muir K, El-Dairi M. Longitudinal reproducibility of spectral domain optical coherence tomography in children with physiologic cupping and stable glaucoma. J AAPOS. (2019) 23:2612. doi: 10.1016/j.jaapos.2019.05.012

31. Go MS, Barman NR, Kelly MP, House RJ, Rotruck JC, El-Dairi MA, et al. Overhead mounted optical coherence tomography in childhood glaucoma evaluation. J Glaucoma. (2020) 29:742-9. doi: 10.1097/IJG.0000000000001567

32. Perucho-González L, de La Casa JMM, Sáenz-Francés F, Morales-Fernandez L, Méndez-Hernández CD, Sánchez-Jean R, et al. Retinal nerve fiber layer thickness in children with primary congenital glaucoma measured by spectral domain optical coherence tomography. J AAPOS. (2019) 23:914. doi: 10.1016/j.jaapos.2017.03.023

33. Pilat AV, Shah S, Sheth V, Purohit R, Proudlock FA, Abbott J, et al. Detection and characterisation of optic nerve and retinal changes in primary congenital glaucoma using hand-held optical coherence tomography. BMJ Open Ophthalmol. (2019) 4:e194. doi: 10.1136/bmjophth-2018-000194

34. Lever M, Halfwassen C, Unterlauft JD, Bechrakis NE, Manthey A, Böhm M. The Paediatric glaucoma diagnostic ability of optical coherence tomography: a comparison of macular segmentation and peripapillary retinal nerve fibre layer thickness. Biology. (2021) 10:260. doi: 10.3390/biology10040260

35. Moher D, Liberati A, Tetzlaff J, Altman DG. Preferred reporting items for systematic reviews and meta-analyses: the PRISMA statement. PLoS Med. (2009) 6:e1000097. doi: 10.1371/journal.pmed.1000097

36. Stroup DF, Berlin JA, Morton SC, Olkin I, Williamson GD, Rennie D, et al. Meta-analysis of observational studies in epidemiology: a proposal for reporting. Meta-analysis of observational studies in epidemiology (MOOSE) group. JAMA. (2000) 283:2008-12. doi: 10.1001/jama.283.15.2008

37. Bowd C, Weinreb RN, Williams JM, Zangwill LM. The retinal nerve fiber layer thickness in ocular hypertensive, normal, and glaucomatous eyes with optical coherence tomography. Arch Ophthalmol. (2000) 118:226. doi: 10.1001/archopht.118.1.22

38. Schuman JS, Hee MR, Puliafito CA, Wong C, Pedut-Kloizman T, Lin CP, et al. Quantification of nerve fiber layer thickness in normal and glaucomatous eyes using optical coherence tomography. Arch Ophthalmol. (1995) 113:58696. doi: 10.1001/archopht.1995.01100050054031

39. Varma R, Bazzaz S, Lai M. Optical tomography-measured retinal nerve fiber layer thickness in normal latinos. Invest Ophthalmol Vis Sci. (2003) 44:336973. doi: 10.1167/iovs.02-0975

40. Turk A, Ceylan OM, Arici C, Keskin S, Erdurman C, Durukan AH, et al Evaluation of the nerve fiber layer and macula in the eyes of healthy children using spectral-domain optical coherence tomography. Am J Ophthalmol. (2012) 153:552-9. doi: 10.1016/j.ajo.2011.08.026

41. Zhu BD, Li SM, Li H, Liu LR, Wang Y, Yang Z, et al. Retinal nerve fiber layer thickness in a population of 12-year-old children in central China measured by iVue-100 spectral-domain optical coherence tomography: the Anyang childhood eye study. Invest Ophthalmol Vis Sci. (2013) 54:810411. doi: $10.1167 /$ iovs.13-11958

42. Rotruck JC, House RJ, Freedman SF, Kelly MP, Enyedi LB, Prakalapakorn SG, et al. Optical coherence tomography normative peripapillary retinal nerve fiber layer and macular data in children 0-5 years of age. Am J Ophthalmol. (2019) 208:323-30. doi: 10.1016/j.ajo.2019.06.025

43. Larsson E, Molnar A, Holmström G. Repeatability, reproducibility and interocular difference in the assessments of optic nerve OCT in children- a Swedish population-based study. BMC Ophthalmol. (2018) 18:270. doi: 10.1186/s12886-018-0940-x

44. Yanni SE, Wang J, Cheng CS, Locke KI, Wen Y, Birch DG, et al. Normative reference ranges for the retinal nerve fiber layer, macula, and retinal layer thicknesses in children. Am J Ophthalmol. (2013) 155:35460. doi: 10.1016/j.ajo.2012.08.010

45. El-Dairi MA, Asrani SG, Enyedi LB, Freedman SF. Optical coherence tomography in the eyes of normal children. Arch Ophthalmol. (2009) 127:508. doi: 10.1001/archophthalmol.2008.553

46. Mocan MC, Machen L, Jang I, Cao D. the relationship between optic nerve cup-to-disc ratio and retinal nerve fiber layer thickness in suspected pediatric glaucoma. J Pediat Ophth Strab. (2020) 57:906. doi: 10.3928/01913913-20200117-02

47. González-García AO, Vizzeri G, Bowd C, Medeiros FA, Zangwill LM, Weinreb RN. Reproducibility of RTVue retinal nerve fiber layer thickness and optic disc measurements and agreement with Stratus optical coherence tomography measurements. Am J Ophthalmol. (2009) 147:1067-74. doi: 10.1016/j.ajo.2008.12.032

48. Baniasadi N, Paschalis EI, Haghzadeh M, Ojha P, Elze T, Mahd M, et al. Patterns of retinal nerve fiber layer loss in different subtypes of open angle glaucoma using spectral domain optical coherence tomography. J Glaucoma. (2016) 25:865-72. doi: 10.1097/IJG.0000000000000534

49. Hua Z, Fang Q, Sha X, Yang R, Hong Z. Role of retinal nerve fiber layer thickness and optic disk measurement by oct on early diagnosis of glaucoma. Eye Sci. (2015) 30:7-12. doi: 10.3969/j.issn.1000-4432.2015.01.002

50. Maurice C, Friedman Y, Cohen MJ, Kaliner E, Mimouni M, Kogan $\mathrm{M}$, et al. Histologic RNFL thickness in glaucomatous versus normal human eyes. J Glaucoma. (2016) 25:447-51. doi: 10.1097/IJG.00000000000 00286

51. Wu H, de Boer JF, Chen TC. Diagnostic capability of spectral-domain optical coherence tomography for glaucoma. Am J Ophthalmol. (2012) 153:81526. doi: 10.1016/j.ajo.2011.09.032

52. Lee VW, Mok KH. Retinal nerve fiber layer measurement by nerve fiber analyzer in normal subjects and patients with glaucoma. Ophthalmology. (1999) 106:1006-8. doi: 10.1016/S0161-6420(99) 00524-2

53. Lee EJ, Kim TW, Kim JA, Kim GN, Kim JM, Girard M, et al. Elucidation of the strongest factors influencing rapid retinal nerve fiber layer thinning in glaucoma. Invest Ophthalmol Vis Sci. (2019) 60:334351. doi: 10.1167/iovs.18-26519 
54. Lee EJ, Kim TW, Kim H, Lee SH, Girard M, Mari JM. Comparison between lamina cribrosa depth and curvature as a predictor of progressive retinal nerve fiber layer thinning in primary open-angle glaucoma. Ophthalmol Glaucoma. (2018) 1:44-51. doi: 10.1016/j.ogla.2018.05.007

55. Wu XS, Xu L, Jonas JB, Zhang L, Yang $\mathrm{H}$, Chen CX. Agreement between spectral domain optical coherence tomography and retinal nerve fiber layer photography in chinese. J Glaucoma. (2012) 21:22833. doi: 10.1097/IJG.0b013e3182070cc6

56. Sung KR, Kim DY, Park SB, Kook MS. Comparison of retinal nerve fiber layer thickness measured by Cirrus $\mathrm{HD}$ and Stratus optical coherence tomography. Ophthalmology. (2009) 116:1264-70. doi: 10.1016/j.ophtha.2008. 12.045

57. Folgar FA, Yuan EL, Farsiu S, Toth CA. Lateral and axial measurement differences between spectral-domain optical coherence tomography systems. J Biomed Opt. (2014) 19:16014. doi: 10.1117/1.JBO.19.1.016014

58. Kansal V, Armstrong JJ, Pintwala R, Hutnik C. Optical coherence tomography for glaucoma diagnosis: an evidence based meta-analysis. PLoS ONE. (2018) 13:e190621. doi: 10.1371/journal.pone.0190621

59. Qu D, Lin Y, Jiang $\mathrm{H}$, Shao $\mathrm{Y}$, Shi $\mathrm{Y}$, Airen $\mathrm{S}$, et al. Retinal nerve fiber layer (RNFL) integrity and its relations to retinal microvasculature and microcirculation in myopic eyes. Eye Vis. (2018) 5:25. doi: 10.1186/s40662-018-0120-3

Conflict of Interest: The authors declare that the research was conducted in the absence of any commercial or financial relationships that could be construed aspotential conflicts of interest.

Publisher's Note: All claims expressed in this article are solely those of the authors and do not necessarily represent those of their affiliated organizations, or those of the publisher, the editors and the reviewers. Any product that may be evaluated in this article, or claim that may be made by its manufacturer, is not guaranteed or endorsed by the publisher.

Copyright (c) 2021 Wen, Zhu and Zhuo. This is an open-access article distributed under the terms of the Creative Commons Attribution License (CC BY). The use, distribution or reproduction in other forums is permitted, provided the original author(s) and the copyright owner(s) are credited and that the original publication in this journal is cited, in accordance with accepted academic practice. No use, distribution or reproduction is permitted which does not comply with these terms. 